\title{
Text Type and the Position of a Temporal Adverbial within the Sentence
}

\author{
Janet Hitzeman
}

\begin{abstract}
:
In this document, I argue that a sentence with a certain type of temporal adverbial is ambiguous, and that one reading is lost when the adverbial appears in sentenceinitial position. Sentence (1a), for example, has a reading in which there was some three-year period in the past during which Mary lived in Amsterdam and a reading in which Mary has lived in Amsterdam for the three years preceding speech time:
\end{abstract}

(1) a. Mary has lived in Amsterdam for three years.

b. For three years Mary has lived in Amsterdam.

Sentence (1b) has only the reading in which Mary lives in Amsterdam at speech time and has done so for the preceding three years. The reading that remains when the adverbial is in sentence-initial position is more specific about the time at which the event occurs, and therefore one would expect to see more initial-position adverbials in a narrative text, where the order of events is important. In testing this hypothesis on the ECI corpus, it was found that it is not the narrative/nonnarrative distinction that results in a significant difference in initial-position adverbial usage; Instead, narratives with a large amount of flashback material have significantly more initial position adverbials, indicating that in order to accurately predict adverbial position a subclassification of the category "narrative" based on amount of flashback material is needed.

Dagstuhl Seminar Proceedings 05151

Annotating, Extracting and Reasoning about Time and Events

http://drops.dagstuhl.de/opus/volltexte/2005/317 


\section{Introduction}

The purpose of this document is to explore the difference in interpretation that arises when a temporal adverbial appears in sentence-initial and sentence-final positions and how text type influences the frequency of initial-position adverbials.

It has often been noted that sentences such as (2) are ambiguous:

(2) Mary has lived in Amsterdam for three years.

Sentence (2) has a reading in which there is some three-year interval in the past during which Mary lived in Amsterdam, and a reading in which Mary lives in Amsterdam at speech time and has done so for the three years preceding speech time. Dowty [1979] argues that one reading is associated with sentence-level attachment of the adverbial and the other with VP-level attachment, and this is bourne out by the observation that when the adverbial is in initial position (where it can only attach at sentence-level) there is only one reading, as below:

(3) For three years Mary has lived in Amsterdam.

Sentence (3) has only the reading in which Mary lives in Amsterdam at speech time and has done so for the preceding three years. I will show that this ambiguity is also present in sentences in the simple tenses, and that the reading of (3) is one in which narrative progression is followed in a strict fashion, i.e., the event described in (3) must occur just after the previously mentioned event, while there is a reading of (2) in which this constraint does not apply. I will then give evidence that certain text types prefer having the adverbial in initial position.

I will begin by describing the relevant data and providing a test that shows that a sentence with a temporal adverbial is ambiguous in the simple tenses as well as the perfect tenses, and that this ambiguity is common to all adverbials of this sort. After showing that one reading is associated with narrative progression, I will discuss how different text types influence the likelihood of an adverbial appearing in sentence-initial position.

\section{The simple tense data}

The purpose of this section is to describe the two readings associated with each adverbial and to show that a sentence with a temporal adverbial is indeed ambiguous in the simple tenses as well as in the perfect. I will begin by discussing the simple future tense sentences and introducing a test for the presence of these readings. There are exceptions to the generalisations I will make about these readings; I will discuss these exceptions in Section 2.2.

Reichenbach's [1947] treatment of tense now becomes relevant to this discussion, so I will briefly review it here. Reichenbach proposes to represent tense in terms of temporal relations between three time points: the point of event $E$ (the time at which the event occurs), the speech time $S$ (the time at which the sentence is spoken), and the point of reference $R$. In the past perfect sentence below, for example, $E$ is the point at which John's boss asks him to 
phone in, $S$ is the time the sentence was spoken, and $R$ is the point from which the event of John's boss asking him to phone in is viewed, namely the time that John picks up the phone:

(4) John picked up the phone. His boss had asked him to phone in.

The function of the past perfect here is to situate the event of asking prior to the event of John's picking up the phone, which, in turn, is prior to speech time. In contrast, in the simple past sentence of (4) the eventuality of John's picking up the phone precedes $S$ but the time from which the event is viewed, $R$, is considered to be simultaneous with $E$. The translations proposed by Reichenbach for the tenses of English are below, where "x_y" means that $x$ precedes $y$, and " $\mathrm{x}, \mathrm{y}$ " means that $x$ and $y$ are simultaneous:

(5) Simple past: R,E_S

Simple future: $\mathrm{S}, \mathrm{R} \_\mathrm{E}$

Simple present: $\mathrm{S}, \mathrm{R}, \mathrm{E}$

Present perfect: E_S,R

Past perfect: E_R_S

Future perfect: S_E_R

I will refer to these as tense templates. In general, the perfect forces $E$ to precede $R$. In the simple past, simple present and present perfect tenses $R$ is simultaneous with either $S$ or $E$, and therefore these tenses are represented with tense templates having only two distinct time points. Whether $R$ is simultaneous with $S$ or $E$ in these templates is important for the interpretation of temporal adverbials, as we shall see.

(Reichenbach actually suggests that the translation for the simple future tense is ambiguous between $\mathbf{S}, \mathbf{R} \_\mathbf{E}$ and $\mathbf{S} \_\mathbf{R}, \mathbf{E}$, but he adds the latter translation to deal with sentences containing the temporal adverbs now and tomorrow. I agree that temporal adverbials affect the order of $S, R$ and $E$ (and I in fact argue in Hitzeman [1993, in press] that other changes are possible), but without adverbs the basic translations in (5) are sufficient. In addition, the fact that the readings associated with the type of temporal adverbial I discuss here interact with the translations in (5) (as we shall see) is additional evidence that these are the appropriate translations for sentences without adverbs, and that it is the adverb that affects the translation rather than the translation itself that is ambiguous.)

\subsection{The ambiguity}

Consider the following examples of in-phrases:

(6) a. Smith \& Co. will build a bridge in ten weeks.

b. In ten weeks Smith \& Co. will build a bridge.

Sentence $(6 \mathrm{a})$ has two readings. The first reading is one in which it takes ten weeks for the bridge to be built, as illustrated in (7):

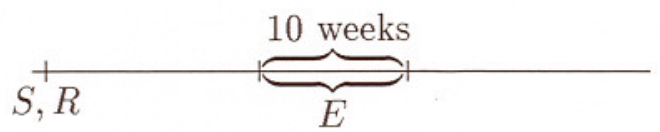


The only known relationship between $E$ and $S$ is that $E$ is some time after $S(=R)$, as indicated by the future tense. The second reading of (6a) is one in which ten weeks pass before Smith \& Co. begin building the bridge, as illustrated in (8):

(8)

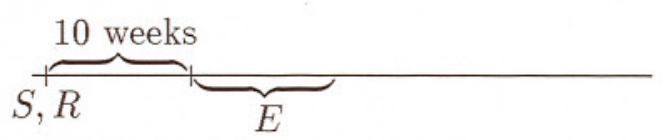

The reading in (8) is the only reading available when the adverbial is in initial position, as in (6b). An initial description of the generalisation concerning the readings of a sentence with a temporal adverbial which I will argue for is that one reading places more constraints on the time of $E$. The phrase ten weeks in the readings illustrated in (7a) can refer to any ten week interval after $R$, while, in its interpretation in (8), it is constrained so that it must refer to the ten-week interval beginning at $R$. Of course, in the simple future tense $\mathrm{R}=\mathrm{S}$, so it is not clear from these data whether it is $\mathrm{R}$ involved here or $\mathrm{S}$. In section $2.3 \mathrm{I}$ will show that it is $\mathrm{R}$ rather than $\mathrm{S}$ that is important here, but for the moment I will allow for both possibilities.

I will adopt Klein's [1992] term position-definite (p-definite) to refer to an NP when (in appropriate context) its content fixes the position of a time span on the time axis as in (8), and I will call it non-p-definite when it is interpreted as expressing a time span whose position on the timeline is vague, as illustrated in (7) - We know that the NP refers to a ten-week interval after $S$, but we don't know the exact position of this interval, so it could be any one of an infinite set of such intervals (constrained, of course, by factors such as context and world knowledge). For example, 2:00 P.M. on January 9, 1983 is p-definite regardless of context since it refers to a particular time on the time axis, and expressions such as yesterday are p-definite in a context where the day of the utterance is known. I will add to this the definition of optionally p-definite to refer to expressions such as Sunday, which are p-definite when referring to a particular Sunday in sentences such as (9a) but which can also appear in sentences with a habitual interpretation such as (9b), in which Sunday refers not to a p-definite Sunday but to a series of non-p-definite Sundays:

(9) a. John went to the library on Sunday.

b. John often goes to the library on Sunday.

Measure terms are also optionally p-definite: two hours can refer to any two-hour period or to a particular two-hour period. To see the ambiguity in a sentence with a temporal adverbial, it is crucial that the NP object of the adverbial be optionally p-definite; only with such an object can the sentence have both a p-definite and a non-p-definite reading.

A similar contrast can be found with for-phrases: ${ }^{1}$

(10) a. Martha will be in her office for an hour.

b. For an hour Martha will be in her office.

Sentence (10a) has both a non-p-definite reading in which Martha will be in her office for some unspecified hour in the future and a p-definite reading in which Martha will be in her office for the hour beginning at $R(=S)$. These readings are illustrated in (11) and (12), respectively:

\footnotetext{
${ }^{1}$ This was pointed out to me by Marc Moens.
} 
(11)

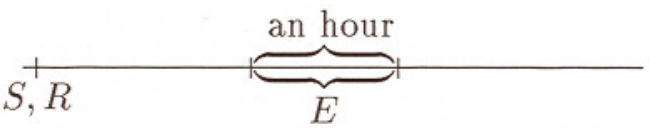

(12)

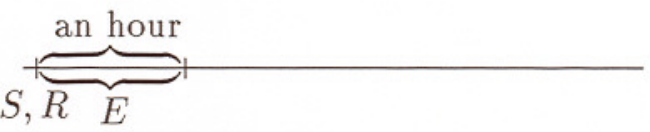

As with in, when the adverbial is in initial position the non-p-definite reading is unavailable; the only available reading of sentence $(10 \mathrm{~b})$ is that Martha will be in her office for an hour beginning at $R(=S)$. The contrast is more clearly seen when the presence of another adverbial forces the non-p-definite reading, as below:

(13) a. Martha will be in her office for an hour one day next week.

b. Martha will be in her office one day next week for an hour.

c. \#For an hour Martha will be in her office one day next week.

d. \#One day next week for an hour Martha will be in her office.

The phrase one day next week moves the one-hour interval into the future so that the p-definite reading, in which the one-hour interval begins at $R(=S)$, is ruled out. The awkwardness of the sentence when the for-phrase is in initial position, as in (13c) and (d), shows that the non-p-definite reading is incompatible with the for-phrase in this position. I will use the acceptability of phrases such as one day next week, once and some day as tests for the nonp-definite reading.

In-phrases can have a different type of reading with certain objects, such as 1993:

(14) The World Trade Center was bombed in 1993.

These $i n$-phrases are similar to on- and during-phrases in that they give the interpretation that the eventuality is included in the time expressed by their NP object. I will call these the inclusive readings because they are characterised by the eventuality's inclusion within some temporal interval. These adverbials also each give a sentence two readings, one of which is unavailable when the adverbial is in initial position. To see this contrast it is again crucial to use a prepositional object that is optionally p-definite, such as the summer. The following examples show the contrast in readings and the difference in the ways that an optionally p-definite NP can be interpreted:

(15) a. John will live in Brooklyn in the summer.

b. In the summer John will live in Brooklyn.

(16) a. Chris will get a phone call during the 11:00 news.

b. During the 11:00 news Chris will get a phone call.

(17) a. The rain will begin on Saturday.

b. On Saturday the rain will begin.

Sentence (15a) has a reading in which John will live in Brooklyn in the summer most closely following $R(=S)$ and a reading in which there is a summer in the future during which John will live in Brooklyn which can be any summer in the future. Only the former, p-definite reading is available when the adverbial is in initial position as in (15b). Evidence for this is that the phrase some day is acceptable in (15a) but not $(15 \mathrm{~b})$ : 
(18) a. John will live in Brooklyn in the summer some day.

b. \#In the summer John will live in Brooklyn some day.

At-, after-and before-phrases relate the time of the eventuality to a point or interval in time. Like the adverbial phrases headed by in and for, they have two readings when their object is optionally p-definite:

(19) a. Martha will be in her office at noon.

b. At noon Martha will be in her office.

(20) a. Leslie will be in Boston before noon.

b. Before noon Leslie will be in Boston.

(21) a. Leslie will be in Boston after noon.

b. After noon Leslie will be in Boston.

In the specific reading of (19a) the eventuality is interpreted as occurring at the noon most closely following $R(=S)$ (or, more precisely, that noon is included in the time at which the eventuality occurs), and in the other reading it is a non-p-definite noon. Only the former reading is available when the adverbial is in initial position as in (19b), as can be seen by the unacceptability of the phrase one day next week when the adverbial is in initial position:

(22) a. Martha will be in her office at noon one day next week.

b. \#At noon Martha will be in her office one day next week.

(23) a. Leslie will be in Boston before noon one day next week.

b. \#Before noon Leslie will be in Boston one day next week.

(24) a. Leslie will be in Boston after noon one day next week.

b. \#After noon Leslie will be in Boston one day next week.

Finally, since-phrases exhibit a different set of inclusive readings. There is a p-definite reading of the sentences in (25), which can be paraphrased with "ever since," in which John has lived in Boston for the entire interval between 1984 and $R(=S)$, and there is a non-p-definite reading of $(25 \mathrm{a})$ in which there was an instance of John living in Boston between 1984 and $R(=S)$, say for June of 1989 .

(25) a. John has lived in Boston since 1984.

b. Since 1984 John has lived in Boston.

The p-definite reading, illustrated in (26), is available whether the adverbial is in initial or final position, but the non-p-definite reading, illustrated in (27), is only available when the adverbial is in final position.
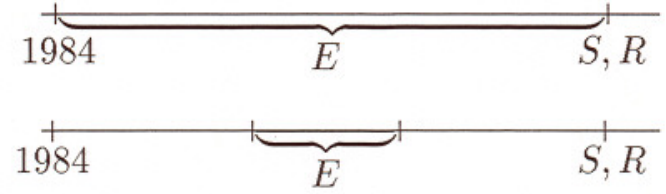

The non-p-definite reading is possible with telic eventualities as well, as in John has changed the oil since his last trip west.

Like the other adverbials, since has two readings, one of which is lost when the adverbial is in initial position. Also like the other adverbials, in one of these readings the eventuality 
is understood to occur at a particular interval and in the other reading the eventuality is understood to occur at an interval whose position is left vague. More precisely, in the p-definite reading the eventuality is understood to occur at the interval between $R(=S)$ and the time expressed by the NP object of since, while in the non-p-definite reading the eventuality is understood to occur at some interval included within the interval between $R$ $(=S)$ and the time expressed by the NP object of since. Since is unusual among temporal adverbials in English because reference time $R$ is always part of its interpretation. Because of this, the test suggested above for distinguishing between the p-definite and non-p-definite readings is not useful with since; adding an additional adverbial to move the eventuality away from reference time is semantically impossible.

\subsection{Apparent exceptions to the generalisation}

The non-p-definite reading is possible in generic sentences [Carlson, 1980] and sentences with a modal operator when the adverbial is in initial position: ${ }^{2}$

(28) a. In one hour Americans consume five million gallons of fuel.

b. In six minutes Martha could gap all twelve plugs.

The simple present tense gives (28a) a generic interpretation, and the modal could indicates that $(28 \mathrm{~b})$ is also a generic sentence. Generic sentences such as these appear to be exceptions to the generalisation that an adverbial in initial position causes the eventuality to be interpreted as occurring at a p-definite time. This is not necessarily the case, however; in Hitzeman [1993, in press] I argue that these data can be explained by an extention to Diesing's [1992] Mapping Hypothesis, illustrated below:

Mapping Hypothesis (tree splitting)

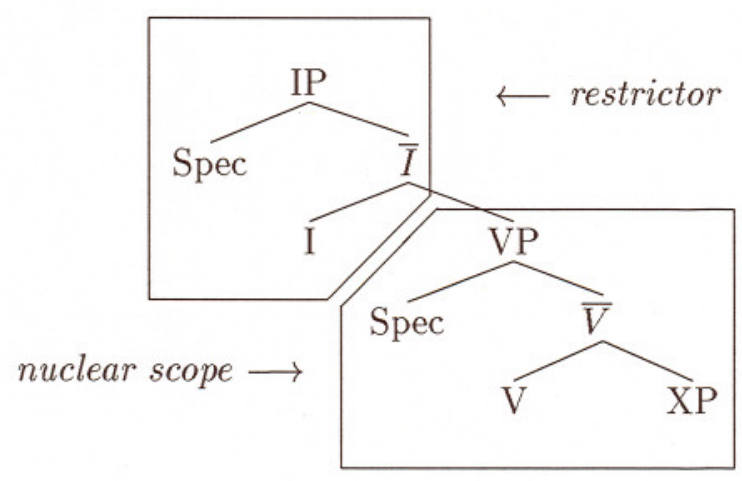

In brief, Diesing proposes that in the mapping from syntax to semantics the syntactic tree is divided into two parts which are mapped onto different semantic correlates. The higher, VP-external portion of the tree is mapped onto the restrictor of some operator and the VPinternal portion is mapped onto the nuclear scope of that operator. If this is, for example, a generic sentence, items in the restrictor are interpreted generically. If there is no operator

\footnotetext{
${ }^{2}$ Example (28a) is due to Derek Gross.
} 
present, items in the restrictor are interpreted as "specific". One example Diesing gives is from Reuland [1988]:

(30) a. Fred denkt dat [IP twee koeien op het dak liggen].

Fred thinks that two cows on the roof lie.

'Fred thinks that two (specific) cows are lying on the roof.'

b. Fred denkt dat $[I P$ er $\quad[V P$ twee koeien op het dak liggen]].

Fred thinks that there two cows on the roof lie

'Fred thinks that there are two cows lying on the roof.'

According to Reuland, when the phrase twee koeien is in subject position as in (30a), the interpretation is that these are two specific cows. In (30b), where er is in subject position and twee koeien is within the VP, the two cows can be interpreted as any two cows. Essentially, VP-internal material is interpreted a s nonspecific, while VP-external material is interpreted as specific.

Another apparent exception is that the non-p-definite reading is available when the adverbial is in initial position if there's a scalar predicate associated with the event, such as flat, only or entire:

(31) In 10 seconds flat/only ten seconds John put the whole puzzle together.

b. In five seconds Floyd ate the entire apple.

In Hitzeman [1993, in press] I argue that these types of expressions are marked lexically as items that must be interpreted as part of either the restrictor or the nuclear scope.

From this point onward I will ignore these readings and concentrate on the more interesting p-definite and non-p-definite readings discussed earlier.

\subsection{The role of time deixis}

We've observed that, in general, adverbials have a p-definite reading and a non-p-definite reading, and the non-p-definite reading is lost when the adverbial is in initial position, but all that's been said concerning the difference between the p-definite and non-p-definite readings is that the p-definite reading places more constraints on the time of the eventuality. How can the p-definite reading be more precisely defined so as to make explicit the relationship it expresses between the time of the eventuality and $R(=S)$ ? Taking a simple future tense sentence with a for-phrase such as Mary will be in the office for an hour the generalisation seems to be that the hour must start at $R(=S)$. In a present perfect example such as Mary has been in her office for an hour, however, the hour is understood to end at $R(=S)$. In the p-definite reading of inclusive in in a simple future sentence such as In the summer John will go to Boston, the summer doesn't begin or end at $R(=S)$, but is the summer most closely following $R(=S)$.

The best generalisation that can be formed concerning the p-definite reading at this point is that the temporal position of the eventuality is definite with respect to $R(=S)$. Here we can make use of the notion of time deixis, which involves interpreting a temporal expression relative to the context of the utterance. For example, the expression yesterday must be 
interpreted relative to speech time, i.e., yesterday, uttered on Day X, can only be used to mean the day before Day $X$. When an expression is interpreted relative to a contextually available time such as $S$ or $R$ as it is in the p-definite reading, I will say that it is interpreted indexically with respect to that time.

The notion of indexical interpretation is useful for all the adverbials but since: The sincephrase describes an interval beginning at (the last moment of) the time expressed by the adverbial's NP object and ending at speech time. In the p-definite ("ever since") reading the eventuality is understood to occur during this entire interval, and in the non-p-definite reading the eventuality is interpreted as occurring at some unspecified time within the interval. For since, therefore, the NP object is always interpreted as p-definite, although the time at which the eventuality occurs is optionally p-definite. It is possible, as Kamp suggests, ${ }^{3}$ that since ought to be treated separately. However, although my definition is inadequate to describe the readings of since, the fact that since fits the pattern of having a p-definite and a nonp-definite reading and that the latter reading is lost when the adverbial is in initial position leads me to believe that since should be grouped with the other adverbials. Having no further suggestions to make in this matter, I will set since aside. The generalisation that is important here is that the reading which is lost when the adverbial is in initial position is one in which the time at which the eventuality occurs is non-p-definite.

\subsection{Summary}

In this section I have described the types of readings a sentence containing a temporal adverbial can have. In general, there are two readings for each adverbial, one of which is unavailable when the adverbial is in initial position. The reading that is unavailable when the adverbial is in initial position is one in which the eventuality is interpreted as occurring at a non-p-definite time. I also introduced the notion of position-definiteness (p-definiteness) which will be useful in identifying optionally p-definite NP objects, which allow both readings of a sentence with a temporal adverbial to appear, and I made the notion of p-definiteness more precise by arguing that in the p-definite reading the time at which the eventuality occurs is interpreted indexically with respect to $R(=S)$.

\section{The effect of tense}

Having shown that each adverbial is associated with two types of readings, I will now discuss the effect of tense on these readings and on the acceptability of a sentence with a temporal adverbial. The questions addressed in this section are as follows:

- In the p-definite reading, is the time at which the eventuality occurs interpreted indexically with respect to $R$ or $S$ ? For example, in the p-definite reading if John will be in the garden at noon, is noon interpreted as the noon most closely following $R$ or $S$ ? This is an important question if we want to generalise over all tenses.

\footnotetext{
${ }^{3}$ Personal communication.
} 
- If a sentence with a temporal adverbial is generally ambiguous, why isn't this true of present perfect sentences which are either unambiguous (e.g., John has lived in Boston in the summer) or unacceptable (e.g., \#On Tuesday John has left)?

(Note that when interpreting the data in this section it is important to avoid a generic or habitual interpretation, which would change the character of the interpretation of the adverbial. See Section 2.2 for discussion.)

\section{Simple Past}

The simple future tense sentences in Section 2 showed that the p-definite reading is one in which the eventuality is constrained to occur at a time that stands in a certain relationship with either $R$ or $S$, which are equivalent in Reichenbach's tense template for the simple future tense. The simple past data gives support to the hypothesis that it is $R$ rather than $S$ that is relevant to the p-definite reading.

Native speaker intuitions are that there is only one reading of a simple past tense sentence with a temporal adverbial:

(32) Mary swam $\left\{\begin{array}{l}\text { for an hour } \\ \text { until noon } \\ \text { in the summer } \\ \text { during the winter } \\ \text { on Tuesday } \\ \text { at noon } \\ \text { before noon } \\ \text { after noon }\end{array}\right.$

However, tests show that there is a different interpretation for a sentence with the adverbial in initial position than when it is in final position. Evidence that the non-p-definite reading is present in the examples in (32) is that they are acceptable with the expression once, which forces the time the eventuality occurs to be non-p-definite:

(33) Mary swam

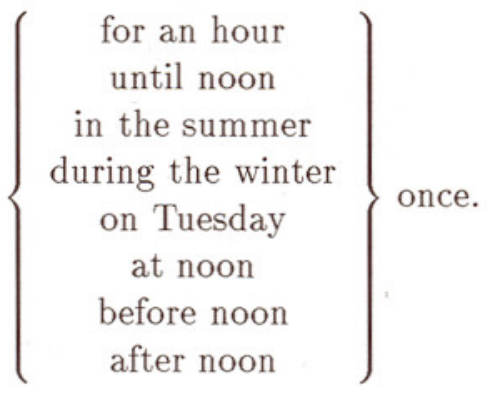

The non-p-definite reading is unavailable when the adverbial is in initial position, as shown by the unacceptability of the expression once in these sentences: 


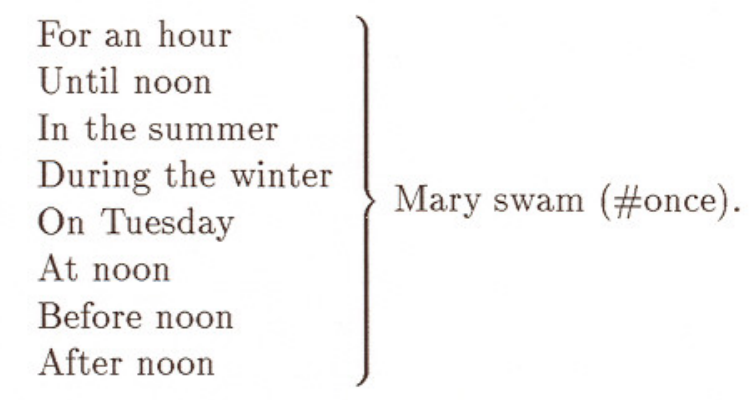

In contrast to the simple future tense examples, the p-definite reading for the simple past tense is not one in which the eventuality stands in a certain relationship to $S$; the hour in For an hour Mary swam is an hour in the past that does not intersect with $S$. The NP object of the adverbial is interpreted indexically in the p-definite reading of a simple past tense sentence as it is in a simple future sentence, however, as the awkwardness of the sentences with once in (34) shows. One possibility is that the indexical interpretation is done with respect to $R$ rather than $S$. Note that while Reichenbach assigns future tense the tense template $\mathbf{S}, \mathbf{R} \_\mathbf{E}$, he assigns past tense the template E,R_S, so that $S$ and $R$ are equivalent in future tense but not in past tense. If we assume $R$ to be used in the indexical interpretation of the NP objects of the adverbials in (34) rather than $S$, we correctly predict the interpretation that the time at which the eventuality occurs is in the past but does not intersect with $S$. From this point on I will assume that the type of indexical interpretation relevant for temporal adverbials is done with respect to $R$.

\section{Past perfect}

The past perfect data reconfirm the generalisation that the non-p-definite reading is lost when the adverbial is in sentence-initial position, and that the p-definite reading is one in which the NP object of the adverbial is interpreted indexically with respect to $R$. The p-definite reading is one in which the final point of the interval on which the eventuality occurred is $R$, as in the sentences in (35):

(35) a. Mary had lived in Boston for six years. She began to consider a move.

b. Sarah had felt confident about her knowledge of ancient Greek until the exam.

The non-p-definite reading in the past perfect is one in which at some non-p-definite interval before $R$ the eventuality occurred:

Mary had been in Boston $\left\{\begin{array}{l}\text { for an hour } \\ \text { until noon } \\ \text { in the summer } \\ \text { during the winter } \\ \text { on Tuesday } \\ \text { at noon } \\ \text { before noon } \\ \text { after noon }\end{array}\right.$

This reading can be paraphrased with once, as in Mary had been in Boston for an hour once. 
In keeping with the generalisation concerning the simple tenses, the non-p-definite reading is lost when the adverbial is in initial position:

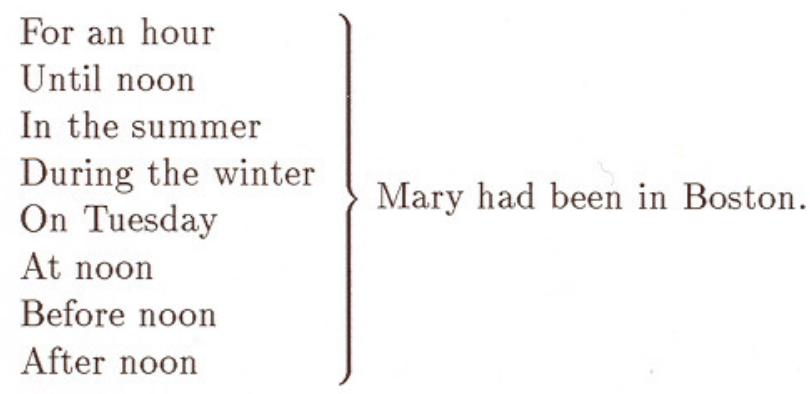

The unavailability of the non-p-definite reading is shown by the unacceptability of these examples with once, as in \#For an hour Mary had been in Boston once.

The future perfect data are similar to the data for past perfect, and are discussed in detail in Hitzeman [1993].

\section{Present perfect}

The present perfect differs from the other tenses we have seen in that it (generally) allows no p-definite reading: in the non-p-definite reading for the present perfect sentences below there is an instance of the eventuality at some non-p-definite time in the past. This reading can be forced by the adverb before:

(38) Mary has swum $\left\{\begin{array}{l}\text { for an hour } \\ \text { until noon } \\ \text { in the summer } \\ \text { during the winter } \\ \text { on Tuesday } \\ \text { at noon } \\ \text { before noon } \\ \text { after noon }\end{array}\right\}$ before.

The interpretation for Mary has swum for an hour before, for example, is that there was a one-hour interval sometime in the past during which Mary swam.

In Mary has swum for an hour, the p-definite reading is one in which Mary has swum for the hour preceding $R(=S)$, paraphrased as Mary has just swum for an hour. The p-definite reading is difficult for until, as shown by the awkward paraphrase \#Mary has just swum until noon.

Placing the adverbial in initial position results in an unacceptable sentences for all the adverbials except for: 


\begin{tabular}{|c|c|}
\hline $\begin{array}{l}\text { For an hour } \\
\text { \#Until noon } \\
\text { \#In the summer } \\
\text { \#During the winter } \\
\text { \#On Tuesday } \\
\text { \#At noon } \\
\text { \#Before noon } \\
\text { \#After noon }\end{array}$ & John has been in the bathtub. \\
\hline
\end{tabular}

The unacceptability of the p-definite reading for most adverbials doesn't fit the generalisation we've made for the other tenses, and requires some explanation.

\subsection{Explaining the present perfect data in terms of time deixis}

In terms of their acceptability in various positions, for and until behave identically except for the p-definite reading in the present perfect tense. This difference can be explained in terms of a difference in the way they specify the time at which an eventuality occurs, as illustrated by the following examples:

(40) a. Martha will be in her office until noon.

b. Martha will be in her office for an hour.

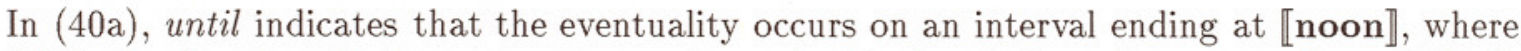
【 』 is the function that maps an expression onto its denotation. In one reading of (40a),

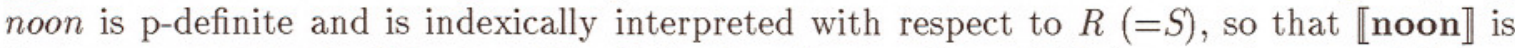
the noon most closely following $R(=S)$. In the other reading of $(40 \mathrm{a})$, noon is non-p-definite,

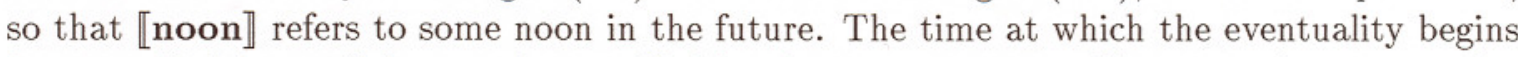
is unspecified by until, but can be specified by the processes controlling narrative progression as in (41) or by context:

(41) Martha will arrive at 10:00. She'll be in her office until noon.

In a simple future tense discourse such as (41) the events are understood to occur sequentially; it is understood that Martha will enter her office just after she arrives and will remain in her office until noon. If we think of an interval as a set of consecutive points on the time axis, the interval during which Martha is in her office can be can be written as a pair of endpoints, $[10: 00$, noon]. Because the initial point of the interval is unspecified for sentence $(40 \mathrm{a})$, the interval can be written as [x, noon], where $\mathbf{x}$ is the initial point of the interval and may be specified by context, world knowledge or other factors. In general an until-phrase will indicate that an eventuality occurs on the interval $[\mathrm{x},($ beg $\llbracket N P \rrbracket)]$, where beg is a function returning the initial point of the time denoted by the NP. ${ }^{4}$ I will refer to this interval as the interval template, and when an endpoint of the interval template is linked to a specific time in the p-definite reading or by the processes controlling narrative progression or other factors, I will say that the interval template has been instantiated.

\footnotetext{
${ }^{4}$ The function beg is necessary for examples in which the NP expresses an interval or event of some duration, such as the party.
} 
The object of a for-phrase expresses not a point but a measured amount of time, so the interval template for for is $[\mathbf{x}, \mathbf{x}+\llbracket \mathbf{N P} \rrbracket]$. For example, in $(40 \mathrm{~b}) \llbracket \mathrm{NP} \rrbracket$ is an amount of time equal to one hour, and the interval template is therefore $[\mathrm{x}, \mathrm{x}+1$ hour]. If the hour is indexically interpreted with respect to $R(=S)$ in the future tense sentence $(40 \mathrm{~b})$, the interval template is instantiated to become $[\mathbf{R}, \mathbf{R}+\mathbf{1}$ hour]. Context or the processes controlling narrative progression may also instantiate the interval template by introducing information concerning when the interval begins or ends, as in (42):

(42) Martha will arrive at 10:00. For an hour she'll be in her office.

The interpretation here is that the hour during which Martha will be in her office begins at 10:00, so the interval template is instantiated as $[\mathbf{1 0 : 0 0 , 1 0 : 0 0 + 1 h o u r ] , ~ o r ~ s i m p l y ~}$ $[10: 00,11: 00] .^{5}$

Recall that the p-definite reading of until is unacceptable with the present perfect while the p-definite reading of for is acceptable:

(43) a. For several minutes Mary has watched the elephants.

b. \#Until noon Mary has been in the bathtub.

The general interval template for for is $[\mathrm{x}, \mathrm{x}+\llbracket \mathrm{NP} \rrbracket]$ and the template for until is $[\mathrm{x},($ beg $\llbracket \mathrm{NP} \rrbracket)]$, so in the examples above the template for for is $[\mathrm{x}, \mathrm{x}+$ several minutes $]$ and for until is [x, noon]. Both for and until give the interpretation that the eventuality occurs during the interval template (in contrast with adverbials such as by and after which give the interpretation that the eventuality occurs before or after the template), so the interval template expresses the event time $E$, and, as described by Reichenbach's tense template for the present perfect $\left(\mathbf{E} \_\mathbf{S}, \mathbf{R}\right), E$ precedes $R(=S)$. The difference arises in the p-definite reading, when the NP is interpreted indexically with respect to $R$ : this reading will cause the final endpoint of each interval template to be equated with $R$, thus giving the interpretation that the eventuality continues (at least) until $R$. Because $R=S$ in present perfect, the eventuality continues (at least) until $S$. For the for-phrase, it is not a problem for the interval to end at $S$, but for the until-phrase this results in a problem with time deixis. Setting the final endpoint of [x, noon] to $S$ means that (43b) is equivalent to (44):

(44) Mary has been in the bathtub until now.

Using noon in (43b) instead of now leads the hearer to believe that another noon is being spoken of. Consider a case in which Mary suggests to John at noon that they go to lunch at noon. The natural interpretation of this suggestion is that she means a noon on another day or that she doesn't know that it is noon. The use of an indexical is necessary in this type of situation, just as it is crucial for me to use the term me instead of Janet to refer to myself. (This is a pragmatic rather than a semantic problem because in certain limited situations it is possible for noon to refer to the current time, as in a case in which Mary is waiting for John, and, knowing it is noon, says to her friend, "He told me he would arrive at noon.")

\footnotetext{
${ }^{5}$ An alternative to these interval templates is that when a for-phrase indicates that the duration of an eventuality $e$ is one hour it is expressed as duration(e,1hour). Then if other factors indicate that the initial point of this one-hour interval is 10:00 as in (42), a statement such as begins(e,10:00) might be added. I use interval templates here because they allow me to show more clearly the interaction of temporal adverbials with the present perfect tense.
} 
In conclusion, the differences in the acceptability of for and until in sentences in the present perfect tense can be accounted for by the difference in their interval templates, causing deictic problems for until but not for. Consider the other adverbials which were unacceptable in a sentence in present perfect tense:

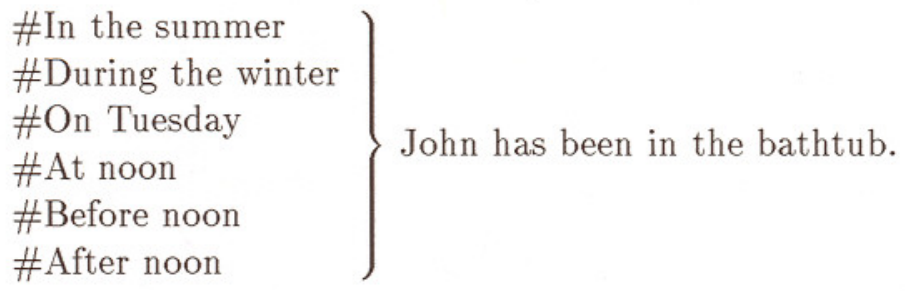

Like until, instantiating the interval templates for these adverbials causes deictic problems, e.g., Tuesday cannot refer to the day on which it is spoken, and the interval template and the present perfect tense combine to produce this pragmatic conflict. Evidence for this explanation is that acceptable sentences can be formed with NPs such as 1989, which can be referred to "by name" when they are ongoing at speech time. For example, (46) is acceptable when spoken during 1989:

(46) In 1989 John has been repeatedly late to practice.

\subsection{Summary}

The data in Section 2 showed that when an English adverbial of the form [P NP] has an optionally p-definite object it gives a sentence two readings, one of which is lost when the adverbial is in initial position. Section 3 then showed that this generalisation holds for all tenses and that the p-definite reading is one in which the time that the eventuality occurs is indexically determined with respect to $R$. The lack of the p-definite reading for most adverbials in a present perfect sentence was attributed to problems with time deixis related to the interval templates for certain adverbials.

\section{The effect of text type}

\subsection{The hypothesis}

I have presented an analysis in which an adverbial in initial position must relate the time of the event to reference time $\mathrm{R}$ while an adverbial in final position is ambiguous between this reading and a reading in which the time of the event is left open. What does this analysis of temporal adverbials mean for different text types? Consider that in a narrative the order of events is more important than in The Financial Times; in the bit of narrative in (47), for example, the events are understood to occur sequentially and this is important for the understanding of the story: 
(47) The Ghost conducted him through several streets familiar to his feet; and as they went along, Scrooge looked here and there to find himself, but nowhere was he to be seen. They entered poor Bob Cratchit's house; the dwelling he had visited before; and found the mother and the children seated round the fire. (Christmas Carol, line 6123)

In the text from The Financial Times in (48), however, the order of events is less crucial.

(48) a. Thus organisations like British Rail and British Gas could use the wayleaves afforded by their railway lines and pipes to provide long-distance telecommunications. Cable $T V$ operators would be allowed to provide local telecommunications services, which for 10 years BT would be excluded from doing. New competitors such as satellite operators would be allowed to operate international links. (FT, line 16490)

b. The suggestions look sensible in themselves; but it does not seem likely that they will win credibility for more than a few months. The reason is political as much as economic: a free-enterprise government can hardly maintain a murderous squeeze on profits for ever, nor can a government nearing election choose to stick to rising unemployment. (FT, line 20462)

More stative sentences and modals appear in The Financial Times and narrative progression is not common. Given that a sentence with a temporal adverbial (with a non-p-definite object) is ambiguous, and, given that English-speakers are able to disambiguate by putting the adverbial in initial position, it is reasonable to hypothesise that there will be more initialposition adverbials in narratives than in texts such as The Financial Times. This hypothesis was tested against the ECI Corpus. The texts chosen were The Financial Times, Far from the Madding Crowd, A Christmas Carol and Silas Marner.

\subsection{The raw data}

Before analysing the data, we eliminated all non-temporal uses of for. We also eliminated examples where the adverbial appeared in the middle of the sentence, as in (49), and examples in which the adverbial modified an NP, as in (50):

(49) I have but to swallow this, and be for the rest of my days persecuted by a legion of goblins, all of my own creation. Humbug, I tell you; humbug! (Christmas Carol, line 1315)

(50) Oil prices of Dollars 50 per barrel for any length of time could push the US and other economies into a fully-fledged recession. Some bond markets may have discounted a short, limited and successful armed conflict with Iraq, but a longer engagement would bring unforeseen pressures. (FT, line 24854)

The analysis of the remaining for-phrases is shown in Tables 1 and 2. Table 1 shows the totals for The Financial Times and the three novels, and Table 2 shows the breakdown of the data for the three novels.

The examples of most interest were those containing optionally p-definite NPs, such as (51): 


\begin{tabular}{|c|c|c|c|c|c|}
\hline & \multicolumn{2}{|c|}{ Financial Times } & \multicolumn{2}{|c|}{3 novels } \\
\hline & & initial & final & initial & final \\
\hline \multirow{7}{*}{ for } & opt-p-def & $5 \mathrm{p} \mathrm{0n}$ & $36 p 4 n$ & $23 \mathrm{p} \mathrm{0n}$ & 116p 21n \\
\hline & p-def & 6 & 18 & 1 & 29 \\
\hline & non-p-def & 1 & 3 & 0 & 0 \\
\hline & generic & \multicolumn{2}{|c|}{14} & \multicolumn{2}{|c|}{14} \\
\hline & perfect & \multicolumn{2}{|c|}{20} & \multicolumn{2}{|c|}{61} \\
\hline & \multirow[t]{2}{*}{ Total } & 12 & 75 & 24 & 180 \\
\hline & & \multicolumn{2}{|c|}{87} & \multicolumn{2}{|r|}{204} \\
\hline
\end{tabular}

Table 1: Comparing The Financial Times with the three novels.

\begin{tabular}{|c|c|c|c|c|c|c|c|}
\hline & \multicolumn{2}{|c|}{ A Christmas Carol } & \multicolumn{2}{|c|}{ Silas Marner } & \multicolumn{2}{|c|}{ Madding Crowd } \\
\hline & & initial & final & initial & final & initial & final \\
\hline \multirow{7}{*}{ for } & opt-p-def & 0 & $11 \mathrm{p} 2 \mathrm{n}$ & $13 \mathrm{p} 0 \mathrm{n}$ & $27 \mathrm{p} 1 \mathrm{n}$ & $8 \mathrm{p} \mathrm{0n}$ & $82 \mathrm{p} 16 \mathrm{n}$ \\
\hline & p-def & 0 & 5 & 0 & 9 & 1 & 15 \\
\hline & non-p-def & 0 & 0 & 0 & 0 & 0 & 0 \\
\hline & generic & \multicolumn{2}{|c|}{1} & \multicolumn{2}{|c|}{4} & \multicolumn{2}{|c|}{8} \\
\hline & perfect & \multicolumn{2}{|c|}{7} & \multicolumn{2}{|c|}{23} & \multicolumn{2}{|c|}{31} \\
\hline & \multirow[t]{2}{*}{ Total } & 1 & 18 & 14 & 40 & 10 & 120 \\
\hline & & \multicolumn{2}{|c|}{19} & \multicolumn{2}{|c|}{54} & \multicolumn{2}{|c|}{130} \\
\hline
\end{tabular}

Table 2: Comparison of the three novels.

(51) It was one of his daily tasks to fetch his water from a well a couple of fields off, and for this purpose, ever since he came to Raveloe, he had had a brown earthenware pot, which he held as his most precious utensil among the very few conveniences he had granted himself. It had been his companion for twelve years, always standing on the same spot, always lending its handle to him in the early morning, so that its form had an expression for him of willing helpfulness, and the impress of its handle on his palm gave a satisfaction mingled with that of having the fresh clear water. (Silas Marner, line 822)

In (51) the adverbial phrase for twelve years can mean either "for some twelve year period in the past" (the non-p-definite reading) or "for the twelve years preceding utterance time" (the p-definite reading), and in this context it takes on the latter reading. These phrases were analysed as to whether they appeared in initial or final position, and also whether their interpretation in context was p-definite or non-p-definite. In Tables 1 and 2 the number of p-definite examples is marked with a "p" and the non-p-definite with an "n".

There were also examples of for-phrases containing an NP whose interpretation was necessarily either p-definite, as in (52), or non-p-definite, as in (53):

(52) a. I'll be plain and open for the rest o' my life." (Silas Marner, line 9057) 
b. 'Let it be, then, let it be,' he said, receiving back the watch at last; "I must be leaving you now. And will you speak to me for these few weeks of my stay? ' (Madding Crowd, line 10643)

(53) The Soviet-backed government in Afghanistan declared an immediate amnesty for prisoners held for up to three years to mark the fourth anniversary of a government drive for reconciliation. (FT, line 858)

In (52) the phrases the rest o' my life and these few weeks of my stay refer unambiguously to particular time intervals in any context, and in (53) the phrase up to three years must refer to an amount of time rather than a particular three year period. Other examples of necessarily non-p-definite phrases include almost 3 weeks, a whole year and six full days. These types of examples were not considered because their position in the sentence does not affect their interpretation. Similarly, examples such as (54) with a generic interpretation were ignored:

(54) a. It has been said that mere ease after torment is delight for a time; and the countenances of these poor creatures expressed it now. Forty-nine operations were successfully performed. (Madding Crowd, line 8424)

b. So, when Priscilla was not with her, she usually sat with Mant's Bible before her, and after following the text with her eyes for a little while, she would gradually permit them to wander as her thoughts had already insisted on wandering. (Silas Marner, line 8438)

In a generic sentence an adverbial can only have a non-p-definite interpretation, e.g., in (54b) a little while doesn't refer to a single time but to a series of (non-p-definite) times during which Priscilla is not present. A present tense (non-reportative) sentence or a sentence with a frequency adverb such as always or a modal such as can are generic.

Finally, the number of examples in perfect tense were counted. These were important as an indication of the amount of flashback material in the text.

\subsection{The results}

The results of the corpus analysis were surprising: There was no significant difference in use of initial-position adverbials between The Financial Times and the narrative texts, as shown in Table 3 which gives the result of the $\chi^{2}$ analysis.

On examining the narrative texts more closely, however, certain significant differences were found. Table 4 shows the result of testing differences in the number of initial-position adverbials in the different narrative texts. (Note that only adverbials with optionally p-definite objects are considered here because these are the only ones which make a sentence ambiguous. See Section 4.2 for discussion.) Here a significant difference was found, which, upon performing pairwise comparisons of the three novels, was attributed to something about the novel Silas Marner; Table 5 shows the pairwise comparisons which evince significant differences in the number of initial-position adverbials in Silas Marner with respect to each of the other two novels.

Given that it is Silas Marner that stands out, a comparison was made between Silas Marner and The Financial Times. This time, significant results were found, as shown in Table 6 . 


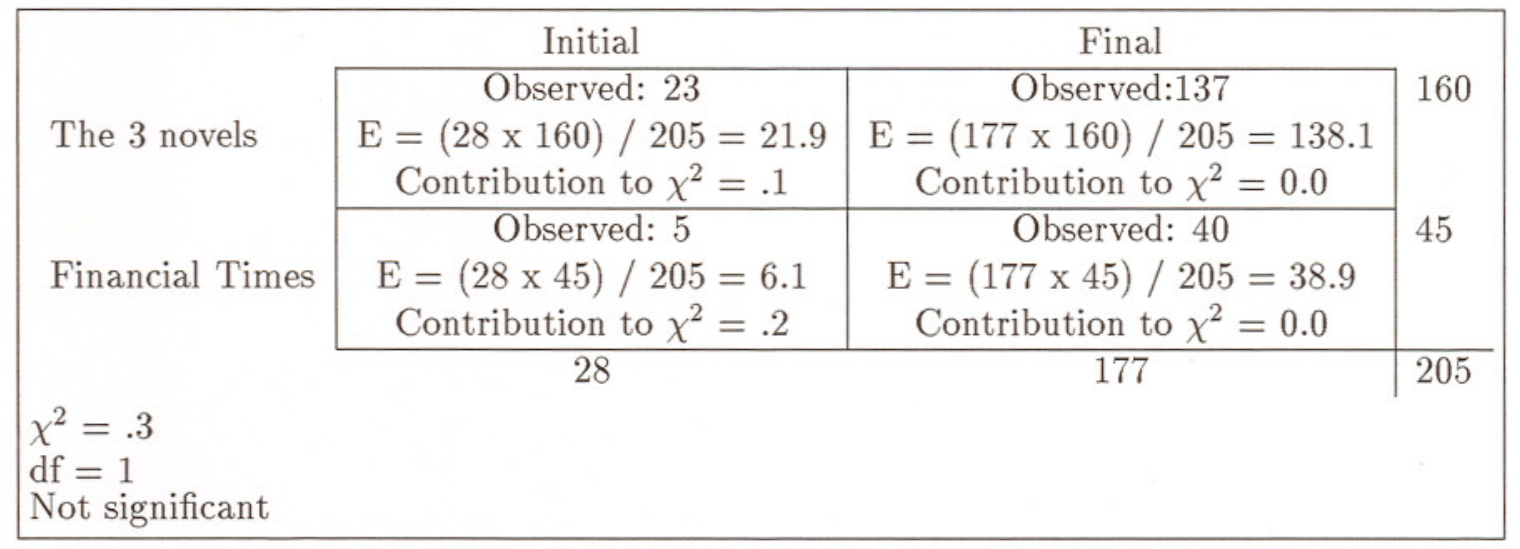

Table 3: $\chi^{2}$ comparison of adverbial position for The Financial Times and the 3 novels.

\begin{tabular}{|c|c|c|c|}
\hline \multirow{4}{*}{ A Christmas Carol } & Initial & Final & \multirow{4}{*}{13} \\
\hline & Observed: 0 & Observed:13 & \\
\hline & $\mathrm{E}=(21 \times 13) / 160=1.7$ & $\mathrm{E}=(139 \times 13) / 160=11.3$ & \\
\hline & Contribution to $\chi^{2}=1.7$ & Contribution to $\chi^{2}=.3$ & \\
\hline \multirow{3}{*}{ Silas Marner } & Observed: 13 & Observed: 28 & \multirow[t]{2}{*}{41} \\
\hline & $\mathrm{E}=(21 \times 41) / 160=5.4$ & $\mathrm{E}=(139 \times 41) / 160=35.6$ & \\
\hline & Contribution to $\chi^{2}=10.7$ & Contribution to $\chi^{2}=1.6$ & \multirow{4}{*}{106} \\
\hline \multirow{4}{*}{ Madding Crowd } & Observed: 8 & Observed: 98 & \\
\hline & $\mathrm{E}=(21 \times 106) / 160=13.9$ & $\mathrm{E}=(139 \times 106) / 160=92.1$ & \\
\hline & Contribution to $\chi^{2}=2.5$ & Contribution to $\chi^{2}=.4$ & \\
\hline & 21 & 139 & 160 \\
\hline \multicolumn{3}{|c|}{$\begin{array}{l}\chi^{2}=17.2 \\
\mathrm{df}=2 \\
\text { Significant with } \rho=.01\end{array}$} & \\
\hline
\end{tabular}

Table 4: $\chi^{2}$ comparison of adverbial position for the 3 novels.

The Financial Times had a significantly greater proportion of adverbials in final position as in $(55)$ :

(55) That said, accusations that the west is adopting double standards in its attitude to Mr Saddam Hussein and Mr Gorbachev are out of place. The annexation of the Baltic states may never have been accepted in international law, but it has been a fait accompli for 50 years. (FT, line 3040)

One possible reason that Silas Marner is different from all of the other texts is that it has stylistic differences. This is not in interesting reason unless we can analyse these differences and incorporate them into our text type taxonomy. One attempt we made to do this was fruitful: We compared the number of for-phrases that occur in perfect sentences in the different texts. The number of perfect sentences serves as an indicator of the amount of flashback material in the text. When perfects are used to signal flashbacks, the amount of ambiguity in the temporal structure of the discourse increases dramatically, and the hypothesis was that as the amount of ambiguity increases the writer will use more initial-position adverbials in order 


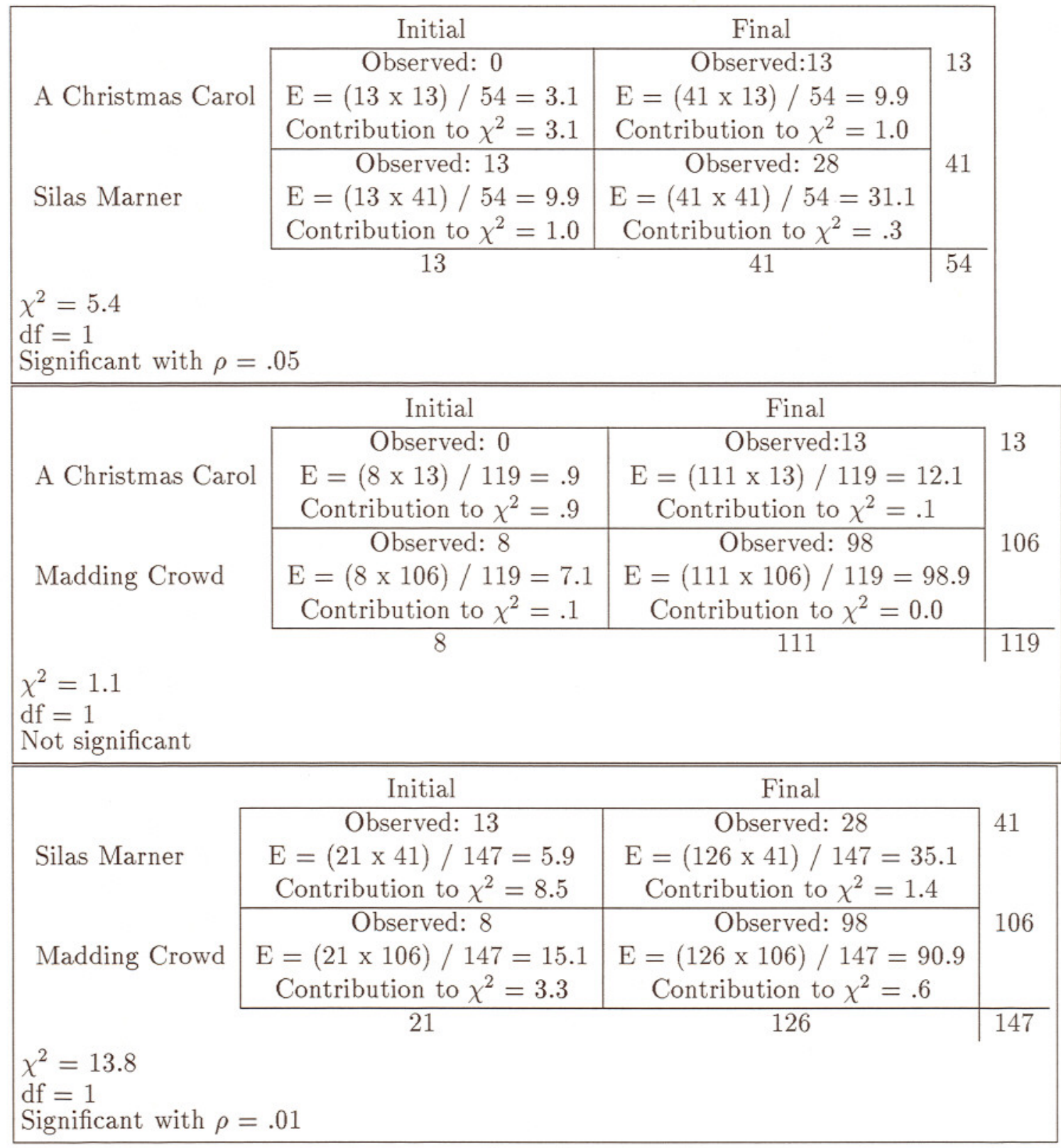

Table 5: $\chi^{2}$ pairwise comparison of the 3 novels. 


\begin{tabular}{|c|c|c|c|c|}
\hline & Initial & Final & & \\
\hline & Observed: 0 & Observed:13 & & 13 \\
\hline A Christmas Carol & $\mathrm{E}=(5 \times 13) / 58=1.1$ & $\mathrm{E}=(53 \times 13) / 58=11$ & & \\
\hline & Observed: 5 & $\begin{array}{c}\text { Contribution to } \chi^{2}=.1 \\
\text { Observed: } 40\end{array}$ & & 45 \\
\hline Financial Times & $\mathrm{E}=(5 \times 45) / 58=3.9$ & $\mathrm{E}=(53 \times 45) / 58=41$ & & \\
\hline & Contribution to $\chi^{2}=.3$ & Contribution to $\chi^{2}=0$. & & \\
\hline & 5 & 53 & & 58 \\
\hline $\begin{array}{l}\chi^{2}=1.5 \\
\mathrm{df}=1 \\
\text { Not significant }\end{array}$ & & & & \\
\hline & Initial & Final & & \\
\hline & Observed: 13 & Observed: 28 & 41 & \\
\hline Silas Marner & $\mathrm{E}=(18 \times 41) / 86=8.6$ & $\mathrm{E}=(68 \times 41) / 86=32.4$ & & \\
\hline & Contribution to $\chi^{2}=2.3$ & Contribution to $\chi^{2}=.6$ & & \\
\hline Financial Times & $\begin{array}{l}\text { Observed: } 5 \\
\mathrm{E}=(18 \times 45) / 86=9.4 \\
\text { Contribution to } \chi^{2}=2.1\end{array}$ & $\begin{array}{c}\text { Observed: } 40 \\
\mathrm{E}=(68 \times 45) / 86=35.6 \\
\text { Contribution to } \chi^{2}=.5\end{array}$ & 45 & \\
\hline & 18 & 68 & 86 & \\
\hline $\begin{array}{l}\chi^{2}=5.5 \\
\text { df }=1 \\
\text { Significant with } \rho=\end{array}$ & & & & \\
\hline & Initial & Final & & \\
\hline & Observed: 8 & Observed: 98 & & 106 \\
\hline Madding Crowd & $\begin{array}{c}\mathrm{E}=(13 \times 106) / 151=9.1 \\
\text { Contribution to } \chi^{2}=.1\end{array}$ & $\begin{array}{l}\mathrm{E}=(138 \times 106) / 151= \\
\quad \text { Contribution to } \chi^{2}=0\end{array}$ & & \\
\hline & Observed: 5 & Observed: 40 & & 45 \\
\hline Financial Times & $\begin{aligned} \mathrm{E}=(13 \times 45) / 151 & =3.9 \\
\text { Contribution to } \chi^{2} & =.3\end{aligned}$ & $\begin{array}{c}\mathrm{E}=(138 \times 45) / 151= \\
\text { Contribution to } \chi^{2}=0\end{array}$ & & \\
\hline & 13 & 138 & & 151 \\
\hline $\begin{array}{l}\chi^{2}=.4 \\
\mathrm{df}=1 \\
\text { Not significant }\end{array}$ & & & & \\
\hline
\end{tabular}

Table 6: $\chi^{2}$ shows significant results for Silas Marner and The Financial Times. 
to keep the amount of ambiguity manageable. As an example of the increase in ambiguity, consider (56):

(56) Brian got to work late. His car hadn't started. He had forgotten to get it fixed.

He had already missed the bus. He took a cab.

In a simple narrative the reader can assume that the events occur in the order described, but in a narrative with flashbacks a deeper understanding of the nature of the events is required in order to understand what happened when. An adverbial in initial position is a cue indicating the order of events. In (57), for example, it's not clear if Michael misses Boston or if he misses the city he lived in before Boston:

(57) Michael had lived in Boston for ten years. He missed his old home.

When the adverbial is in initial position as in (58), however, the ambiguity is eliminated:

(58) For ten years Michael had lived in Boston. He missed his old home.

The results in Table 7 show that there is a significant difference in the number of forphrases in perfect sentences in the three novels. Breaking down the data to look at pairwise comparisons of the novels in Table 8 we see Silas Marner has significantly more of these perfect examples than Far from the Madding Crowd. Similarly, as shown in Table 9, Silas Marner has significantly more perfect examples than The Financial Times, and The Financial Times doesn't show a significant difference in the number of perfect examples from either $A$ Christmas Carol or Far from the Madding Crowd.

Now consider the amount of flashback material the four texts contain: Silas Marner contains a considerable amount ( $43 \%$ of the sentences with a for-phrase were in the perfect) as Silas goes back to the past to clear his name; A Christmas Carol has fewer (37\%) since only one of the ghosts takes Scrooge to the past; and Far from the Madding Crowd (24\%) and The Financial Times $(23 \%)$ contain even fewer since the former is a simple narrative and the

\begin{tabular}{|c|c|c|c|}
\hline \multirow{4}{*}{ A Christmas Carol } & Perfect & No Perfect & \multirow{4}{*}{19} \\
\hline & Observed: 7 & Observed: 12 & \\
\hline & $\mathrm{E}=(61 \times 19) / 203=5.7$ & $E=(142 \times 19) / 203=13.3$ & \\
\hline & Contribution to $\chi^{2}=.3$ & Contribution to $\chi^{2}=.1$ & \\
\hline \multirow{3}{*}{ Silas Marner } & 23 & 31 & \multirow[t]{3}{*}{54} \\
\hline & $\mathrm{E}=(61 \times 54) / 203=16.2$ & $\mathrm{E}=(142 \times 54) / 203=37.8$ & \\
\hline & Contribution to $\chi^{2}=2.9$ & Contribution to $\chi^{2}=1.2$ & \\
\hline \multirow{4}{*}{ Madding Crowd } & 31 & 99 & \multirow[t]{3}{*}{130} \\
\hline & $\mathrm{E}=(61 \times 130) / 203=39.1$ & $\mathrm{E}=(142 \times 130) / 203=90.9$ & \\
\hline & Contribution to $\chi^{2}=1.7$ & Contribution to $\chi^{2}=.7$ & \\
\hline & 61 & 142 & 203 \\
\hline \multicolumn{4}{|c|}{$\begin{array}{l}\chi^{2}=6.9 \\
\mathrm{df}=2 \\
\text { Significant with } \rho=.05\end{array}$} \\
\hline
\end{tabular}

Table 7: $\chi^{2}$ comparison of the number of for-phrases that occur in perfect sentences for the 3 novels. 


\begin{tabular}{|c|c|c|c|c|}
\hline \multirow{4}{*}{ A Christmas Carol } & Perfect & No Perfect & \multirow[b]{2}{*}{19} & \\
\hline & Observed: 7 & Observed: 12 & & \\
\hline & $\mathrm{E}=(30 \times 19) / 73=7.8$ & $\mathrm{E}=(43 \times 19) / 73=11.2$ & \multirow{5}{*}{54} & \\
\hline & Contribution to $\chi^{2}=.1$ & Contribution to $\chi^{2}=.1$ & & \\
\hline \multirow{3}{*}{ Silas Marner } & Observed: 23 & Observed: 31 & & \\
\hline & $\mathrm{E}=(30 \times 54) / 73=22.2$ & $\mathrm{E}=(43 \times 54) / 73=31.8$ & & \\
\hline & Contribution to $\chi^{2}=0.0$ & Contribution to $\chi^{2}=0.0$ & & \\
\hline \multirow{2}{*}{\multicolumn{4}{|c|}{$\begin{array}{l}\chi^{2}=.2 \\
\mathrm{df}=1 \\
\text { Not significant }\end{array}$}} & \\
\hline & & & & \\
\hline \multicolumn{4}{|c|}{ No Perfect } & \multirow{4}{*}{19} \\
\hline \multirow{3}{*}{ A Christmas Carol } & \multirow{3}{*}{$\begin{array}{c}\text { Observed: } 7 \\
\mathrm{E}=(38 \times 19) / 149=4.8 \\
\text { Contribution to } \chi^{2}=1.0\end{array}$} & \multicolumn{2}{|c|}{ Observed: 12} & \\
\hline & & \multirow{2}{*}{\multicolumn{2}{|c|}{$\begin{array}{c}\mathrm{E}=(111 \times 19) / 149=14.2 \\
\text { Contribution to } \chi^{2}=.3\end{array}$}} & \\
\hline & & & & \\
\hline \multirow[t]{2}{*}{ Madding Crowd } & $\begin{array}{c}\text { Observed: } 31 \\
\mathrm{E}=(38 \times 130) / 149=33.2 \\
\text { Contribution to } \chi^{2}=.1\end{array}$ & \multicolumn{2}{|c|}{$\begin{array}{c}\text { Observed: } 99 \\
\mathrm{E}=(111 \times 130) / 149=96.8 \\
\text { Contribution to } \chi^{2}=.1\end{array}$} & 130 \\
\hline & \multicolumn{3}{|l|}{38} & 149 \\
\hline \multicolumn{5}{|l|}{$\begin{array}{l}\chi^{2}=1.5 \\
\mathrm{df}=1 \\
\text { Not significant }\end{array}$} \\
\hline \multicolumn{4}{|c|}{ No Perfect } & \multirow{3}{*}{54} \\
\hline \multirow{3}{*}{ Silas Marner } & Observed: 23 & Observed: 31 & & \\
\hline & $\begin{aligned} \mathrm{E}=(54 \times 54) / 184 & =15.8 \\
\text { Contribution to } \chi^{2} & =3.3\end{aligned}$ & $\begin{array}{c}\mathrm{E}=(130 \times 54) / 184=38 . \\
\text { Contribution to } \chi^{2}=1.4\end{array}$ & & \\
\hline & Observed: 31 & Observed: 99 & & \multirow[t]{2}{*}{130} \\
\hline \multirow[t]{2}{*}{ Madding Crowd } & $\begin{array}{c}\mathrm{E}=(54 \times 130) / 184=38.2 \\
\text { Contribution to } \chi^{2}=1.4\end{array}$ & $\begin{array}{c}\mathrm{E}=(130 \times 130) / 184=91 \\
\quad \text { Contribution to } \chi^{2}=.6\end{array}$ & & \\
\hline & 54 & 130 & & 184 \\
\hline \multicolumn{3}{|c|}{$\begin{array}{l}\mathrm{df}=1 \\
\text { Significant with } \rho=.05\end{array}$} & & \\
\hline
\end{tabular}

Table 8: $\chi^{2}$ pairwise comparison of the number of perfect examples in the 3 novels. 


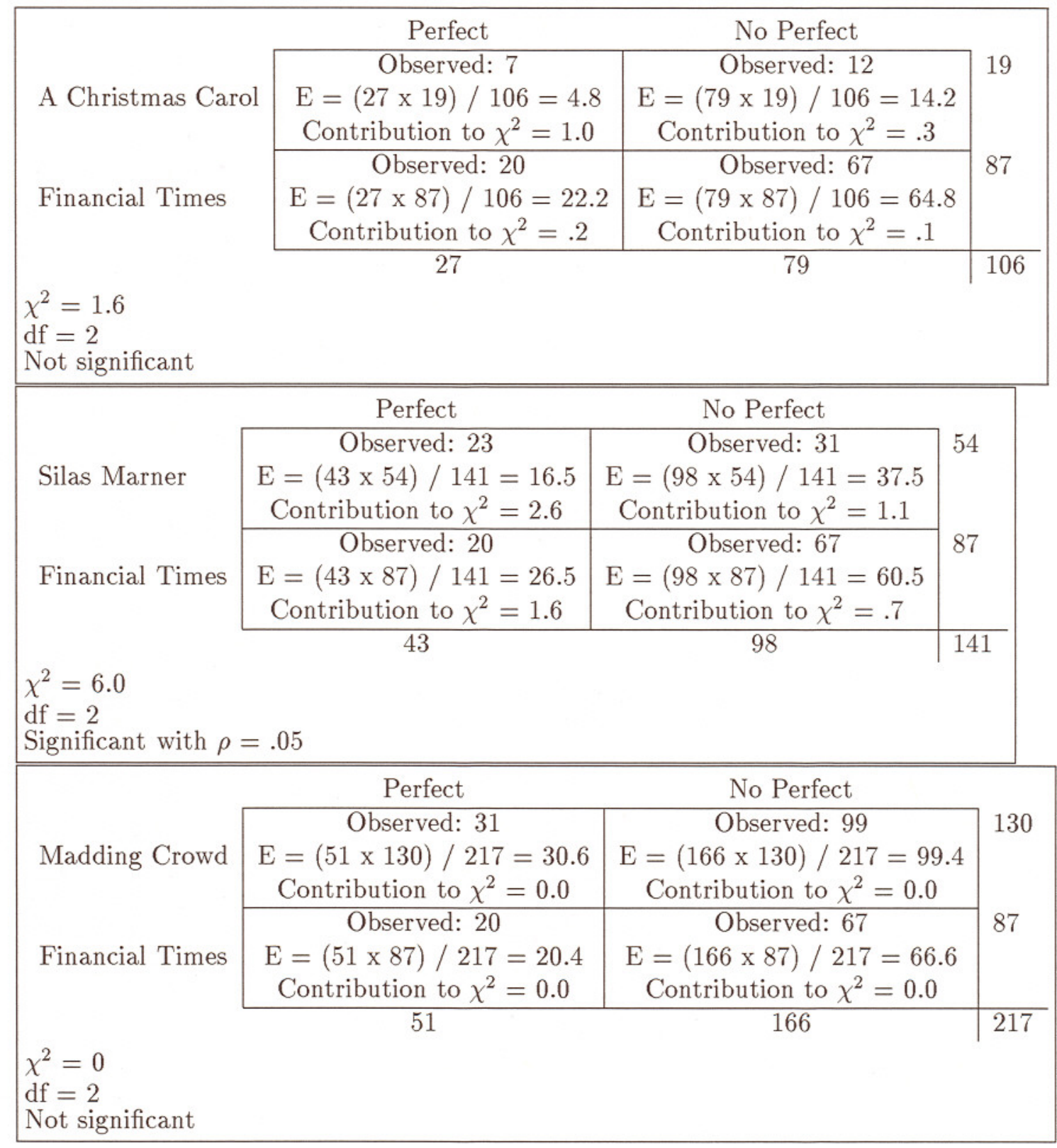

Table 9: $\chi^{2}$ pairwise comparison of perfect examples in The Financial Times with each of the 3 novels. 
latter is a non-narrative text. ${ }^{6}$ The number of perfect sentences serves as a strong indicator of the amount of flashback material, and, it should also be noted, is simple to calculate computationally.

In conclusion, the data indicate that the distinction between narrative and non-narrative texts is not fine enough to adequately predict whether an adverbial is more likely to appear in initial or final position. A comparative analysis of the narratives versus The Financial Times showed no significant difference in the amount of initial or final position adverbials. It was only upon analysing the three narratives individually that Silas Marner, a novel with many flashback scenes, stood out as having more sentence-initial adverbials than the other texts. Narratives must also be categorised according to the amount of flashback material they contain in order to use the categorisation as a reasonable predictor of temporal adverbial position.

\footnotetext{
${ }^{6}$ Of course, The Financial Time contains some narrative just as a narrative will contain some non-narrative text. The categorisations must be taken as characterisations based on the majority of the text rather than absolutes.
} 
[Carlson, 1980] G. Carlson. Reference to kinds in english. In J. Hankamer, editor, Outstanding Dissertations in Linguistics. Harvard University, 1980.

[Diesing, 1992] Molly Diesing. Bare plural subjects and the derivation of logical representations. Linguistic Inquiry, 23(3):353-380, Summer 1992.

[Dowty, 1979] D. R. Dowty. Word Meaning and Montague Grammar. D. Reidel, Dordrecht, Holland, 1979.

[Hitzeman, 1993] J. M. Hitzeman. Temporal Adverbials and the Syntax-Semantics Interface. $\mathrm{PhD}$ thesis, University of Rochester, Department of Linguistics, Rochester, NY, 1993. Also available as TR 931, Cognitive Science Program, University of Rochester.

[Hitzeman, in press] Janet Hitzeman. Semantic partition and the ambiguity of sentences containing temporal adverbials. Journal of Natural Language Semantics.

[Klein, 1992] Wolfgang Klein. The present perfect puzzle. Language, 68(3):525-552, 1992.

[Reichenbach, 1947] Hans Reichenbach. Elements of Symbolic Logic. McMillan, 1947.

[Reuland, 1988] E. Reuland. Indefinite subjects. In Proceedings of NELS 18, pages 375-394, Amerhest, 1988. GLSA, University of Massachusetts. 